SF

538

M57

$\mathrm{B9}$

I)

$x^{2}$

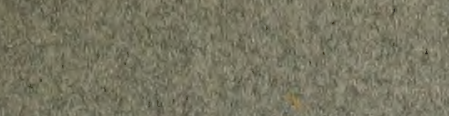

(2)
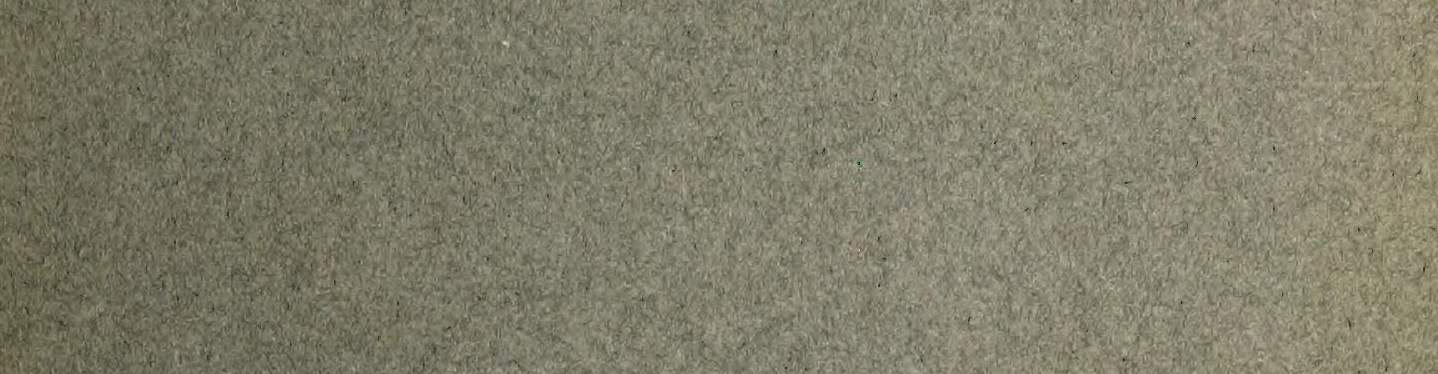

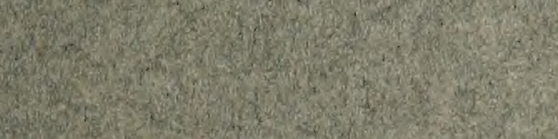

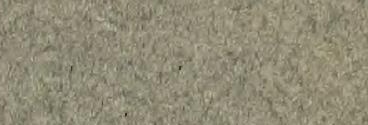
- $x^{2}=0$

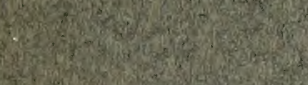




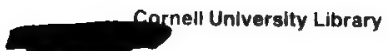

Nosema apis and Acarapis (Tarsonemus) Wo

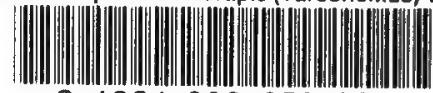

31924003658956 


\title{
NOSEMA APIS AND ACARAPIS (TARSONEMUS) WOODI IN RELATION TO ISLE OF WIGHT BEE DISEASE
}

\author{
GEO. W $\left\{\begin{array}{l}1^{\mathbf{B Y}} \\ \text { BULLAMORE }\end{array}\right.$ \\ Molteno Institute for Research in Parasitology, Cambridge
}

From PARASI'TOLOGY, Vol. XIV, No. 1, 25 ApRI, 1922

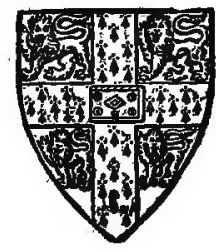

CAMBRIDGE

AT THE UNIVERSITY PRESS

w. W 


\section{Cornell University Library}

The original of this book is in the Cornell University Library.

There are no known copyright restrictions in the United States on the use of the text. 
[From PARASITOLOGY, Vot. XIV, No. 1, 25 April, 1922.]

[All Rights reserved]

\title{
NOSEMA APIS AND ACARAPIS (TARSONEMUS) WOODI IN RELATION TO ISLE OF WIGHT BEE DISEASE.
}

\author{
By GEO. W. BULLAMORE, \\ Molteno Institute for Research in Parasitology, Cambridge.
}

CONTENTS.

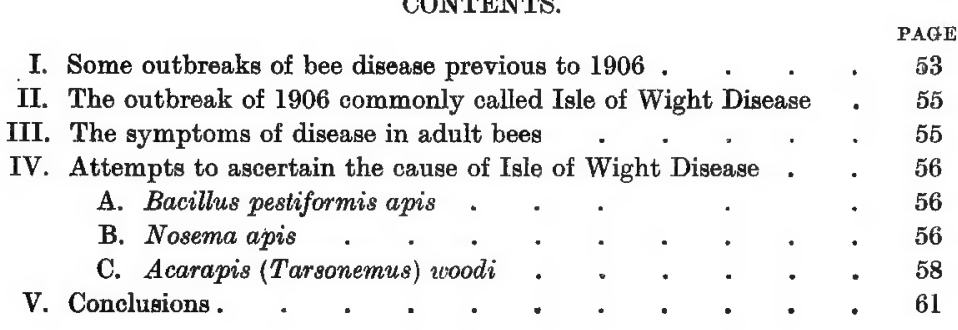

I. Some Outbreaks of Bee Disease previous to 1906.

In former times when this country was dependent upon bees for its supply of sugar, a heavy mortality among these insects was of sufficient importance to be placed on record. In his Animal Plagues Fleming (1871) gives a number of references to such losses. In Ireland there was a "mortality of bees" in 950 A.D. and again in 992 A.D. there was a "great mortality upon men, cattle and bees." In 1035 A.D. the destruction of bees afflicted the whole of Bavaria. An eclipse of the sun in 1124 A.D. was followed by a great pestilence amongst oxen, sheep, pigs, and bees. During the time of the "Black Death," also, there appears to have been heavy losses of bees and at the Manor Court of Heacham in Norfolk, a statement was made on oath by the steward in the forty-fifth year of the reign of Edward III (1372 A.D.) to the effect that ten out of eleven stocks of bees had perished from the murrain. There is little doubt that this entry in the manorial court rolls refers to epidemic disease, but, as Fleming points out, "there is evidently no relationship between the morinâ of the bees and that of the sheep and cows."

The year 1443 A.D. was rainy and tempestuous after May which "much hurted both bees and sheep in Ireland"; while in Italy in 1690 A.D. "bees extracting no sweetness from the calyces of the flowers, but a bitter poison, either died or left the country." A great mortality among bees and carp is also recorded in 1717 A.D. in Silesia.

A well-known writer on bees, Dr Bevan (1837), states that

in the winter of 1782-3, a general mortality took place among the bees in this country, which was attributed to various causes; want of honey was not one of them; for in some 
Missing Page 
hands of many farmers and small owners. A year ago this spring there were upwards of 2000 colonies of bees lost. It was thought a year ago that it was owing to the very cold winter weather and changeable weather in the spring; but the strange part of it is that in some localities not any warmer, but if anything, colder, the bees survived all right, with scarcely any loss at all.

I lost last year 300 colonies of bees, and in some localities in Cache Valley there were upwards of $\mathbf{5 0 0}$ colonies that went under; and in this valley (Salt Lake) last year there were fully 800 colonies that perished. It was thought by all those who were interested that it was due to the hard winter and cold spring.

This writer, who had lost nearly all his stocks, bought 225 colonies in a district that disease had not visited, and moved them into his apiary. $\mathrm{He}$ continues:

I was there yesterday, and a large part of the entire 225 colonies are affected with what appears to be paralysis. While there is no trembling, they drop down in the grass in front of the hives, and are unable to fly; they seem to mount the grass and twigs with great difficulty, and in taking them up in my hands they were unable to fly away, and, if thrown into the air, would drop to the ground. They seemed to have no desire even to sting. It appears to be contagious, for it seems to affect a certain part of a row, while another section of the row seems to be strong and swarming. A number of hives have all gone under. The entire yard, of course, is exposed for the reason that a few, perhaps twenty, colonies from what were left of the lot last year were put with them without any thought of anything being wrong, except that they were weak.

I am fully satisfied now that the loss last year, which would number at least 2000 colonies in Cache Valley, was due entirely to this condition.

\section{The Outbreak of 1906 commonly called Isle of Wight Disease.}

In 1906 we first began to hear of the bees in the Isle of Wight suffering from "paralysis," a disease of world-wide occurrence and of which the cause is unknown. On account of the deadly nature of the Isle of Wight visitation, however, it was afterwards decided that the disease was a new one and the name of Isle of Wight disease came into use. It was found to have been present on the Isle of Wight in 1904, so it was consequently assumed to have then originated and to have spread thence to the mainland. It usually manifested itself by the presence in the apiary of numbers of crawling bees with their abdomens distended with undischarged faeces. In a few months all the colonies in the apiary were dead.

\section{The Symptoms of disease In Adult BeEs.}

The whole subject of bee diseases teems with difficulties, and it is improbable that any method of differentiating them other than the demonstration of the causal organism is likely to prove of value. Inability to $f l y$, which is the chief symptom in any disease of the adult bee, may originate from a variety of causes, e.g. the ingestion of fungi, mineral poisons, fermenting honey, syrup or fruit juice, or from weakness due to starvation.

Inability to fly leads to a retention of the faeces, which are voided normally by the bee in the open air while flying. We find that a crawling bee may be 
slow and sluggish, may run rapidly, may tremble, present a hairless appearance, drag its hind pair of legs helplessly, may be subject to dysenteric discharges, or may impart a yellow colour to the interior of the hive by passing constantly a tiny threadlet of faeces. Possibly the varying manifestation may be due to the multiplication of bacteria of different species or of other parasites in the bowel of the affected bee. Whether the condition is sometimes due to infection it is impossible to decide.

Again, the normal life of the individual bee may vary from eight weeks to as many months according to the activities of the colony, and it may be that organisms which do little harm in two months cause serious trouble where the necessities of the colony require the extension of the lives of its individual members for a longer period.

The difficulty of tracing a connection between a disease and any parasitic organism that may be found in the bee becomes very real when the investigation of disease is attempted. If, while the external conditions are favourable, the organism is fed to a colony as an experiment, the bees may fail to die or to develop symptoms; while if unfavourable conditions prevail at the time of the experiment, death may be due to unrecognised causes, such as infection with $N$. apis (see below). Apparently healthy bees, if prevented from flying, will sometimes develop symptoms (crawling with bowel distention) indistinguishable from Isle of Wight disease.

\section{Attempts to ascertain the Cause of Isle of Wight Disease.}

\section{A. Bacillus pestiformis apis.}

The first to associate a definite causal organism with Isle of Wight disease was the late Dr Walter Malden (1909). He found no macroscopic appearances in the diseased bees that were not to be found in bees from healthy colonies. Microscopically, "no changes were discovered in the salivary glands, brain, fat-body, heart, tracheae, air-sacs, Malpighian bodies, or honey stomach." Changes were found in the chyle stomach, however, and attention was concentrated on that organ. In film preparations made from small portions of the chyle stomachs of diseased bees, teased out on glass slides and stained with methylene blue, a bacillus was found with darkly staining ends and a lightly staining central band, resembling Bacillus pestis in general appearance. This was suggested as having a causal relationship to the disease and the name Bacillus pestiformis apis was proposed. Cultures of this bacillus fed in sugar to bees did not appear to have any harmful effect and the view that it is the organism that caused the disease has been abandoned.

\section{B. Nosema apis.}

In 1907 Dr Enoch Zander (1911) discovered a protozoon in bees which was recognised as being closely related to Nosema bombycis, a parasite which did enormous damage to the silkworm industry in France about the middle 
of the nineteenth century. The organism found in bees was named Nosema apis and Zander looked upon it as the cause of heavy losses in Bavaria. The essential feature of the trouble was a sudden and extensive mortality among the bees inside and outside the hive. Dysentery was an occasional accompaniment. Berlepsch's description of the epidemic of 1859 (see p. 54) is considered by Zander to be a typical description of the ravages of unchecked Nosema disease.

The discovery attracted considerable attention. Maassen (1911) found Nosema to be widely prevalent in German apiaries, but although he looks upon the parasite as pathogenic he considers that unfavourable conditions are necessary for the manifestation of disease.

Nussbaumer (1912) found Nosema in association with heavy losses in Switzerland.

Beuhne (1916) states that Nosema was first discovered in Australia in 1909 , but that observation showed that it was

doubtful whether the presence of the parasite is in itself necessarily fatal, or that it greatly interferes with the productiveness of the hives excepting under certain conditions due to climatic influence....In fact under ordinary conditions the disease is endemic, and becomes epidemic only when the vitality of the bee is impaired by the malnutrition during the bees' larval development which is caused by a dearth, or the inferior quality of the nitrogenous food which bees obtain solely from the pollen of the flowers of plants.

As the result of investigation at Cambridge (Graham-Smith, Fantham, Porter, Malden, and Bullamore 1912) a report was issued showing that Nosema was present in a large percentage of stocks affected with Isle of Wight disease and the disease was attributed to the presence of this parasite.

Later, Anderson and Rennie (1916) working on the Isle of Lewis took up the question of Nosema and Isle of Wight disease. They were unable to corroborate the findings of the Cambridge investigation and state that Nosema was found to be present in stocks without disease symptoms appearing. They did not find Nosema distributed in the bees of all the stocks but only in a few stocks at any one time, and when it occurred "Isle of Wight disease was not present."

The result is somewhat surprising as, assuming that Nosema is a comparatively harmless parasite, its non-occurrence in stocks suffering from Isle of Wight disease seems to require some explanation.

While the work on the Isle of Lewis was being carried on, continuous importations of bees were being made from all parts of the country. Bees, assumed to be healthy, were introduced into the apiary from Scotland, England, Wales, Ireland, America, Switzerland, Austria, and Holland. These bees developed crawling symptoms at periods varying from a week to a month or more after arrival. Consequently it is difficult to determine the disease with which Anderson and Rennie were actually working or to feel sure that importations of other diseases were not being made. The following are the particulars of what is described as a spontaneous recovery. 
Three stocks of bees, one Italian, one Carniolan and one black (British or Dutch?) were imported into the apiary from Devonshire on June 4th, 1915.

During June these three stocks gave off four swarms and the seven colonies were showing crawling symptoms on June 30th. Three of the colonies died owing to faulty queens and another was destroyed by robber bees. A fifth was reinforced by the addition of three pounds of bees (source not stated) and an Italian queen was also given to this colony. Some driven bees from Wales were placed in the apiary. In December, 1915, there were four stocks alive showing no signs of disease.

Accounts of further work by Dr Rennie and Miss Harvey (1919 A and B) are given in the Journal of the Scottish Board of Agriculture. With regard to Nosema the conclusion arrived at is that it "is always a weakening factor, and in the presence of other adverse conditions favourable to the development of dysentery it may become seriously pathogenic to bee stocks." In ordinary circumstances it was not found to destroy colonies in the rapid and virulent manner generally found in Isle of Wight disease. The authors consider that in the latter disease there is no recovery of sick bees nor of affected stocks.

Mention is also made of a temporary sickness which sometimes affected all the bees of a district. "In such cases it would appear to be due to some disturbing factor in the nectar or pollen."

\section{Acarapis (Tarsonemus) woodi.}

In November, 1920, a paper was read before the Royal Society of Edinburgh in which Dr Rennie, in association with Mr Bruce White and Miss Harvey, described a new species of mite from the tracheae of hive bees. This mite, which was named Tarsonemus woodi, was put forward as being the cause of Isle of Wight disease, which was henceforth to be known as "acarine disease." Hirst (1921) considers that the new mite differs sufficiently from Tarsonemus to form a new genus and proposes that the species shall be renamed Acarapis woodi.

The mites gain entrance to the tracheae by means of the first pair of thoracic spiracles. Crawling of bees, followed by the death of the affected colony then takes place. The presence of the mite is not necessarily fatal however, for we read in the Report to the Royal Society of Edinburgh that

Of 140 stocks believed by their owners to be healthy, 50 or nearly 36 per cent. harboured the parasite. Concurrent with such discoveries we ascertained by direct examination ourselves of Alying bees (1) which were members of colonies in which the disease was definitely established and (2) which were taken from colonies believed to be healthy and showing no indications otherwise, that amongst these were to be found considerable numbers harbouring the parasite. This was further complicated by the fact that in those infected flying bees certain of those pathological conditions-e.g. the blackening and hardening of the tracheal tubes-were very marked. As an example it may be quoted that this condition was found in bees entering the hive carrying pollen or nectar, both belonging to stocks in which crawling and other symptoms were well established and also in those reputed healthy
stocks. 
In the record of another stock we read that "the flying workers were frequently more heavily parasitised than were the bees of the same stock which were unable to fly."

In an interesting case which was under the writer's own observation in April, 1921, the crawling symptom was manifested but no mites were to be found. The crawling disappeared during the summer but reappeared in the autumn when the symptom was accompanied by the presence of mites in the tracheae.

As an example of the recovery of a stock we have the following from a letter received by Dr Rennie (1921):

On January 9th I received your report that the bees from one of my stocks had Tarsonemus woodi.

From this stock reported diseased on that date I had a swarm on the 23rd of May and this swarm swarmed on the 28 th of June. I have taken off 150 sections and have three very strong stocks.

Dr Rennie's explanation is that early diagnosis enables us to recognise such recoveries and that formerly this was not possible. We only recognised the presence of the disease after it was irretrievably established. This "gave us an erroneous idea as to the gravity of the disease."

Such an explanation is not altogether satisfactory. When Isle of Wight disease reached an apiary the loss of colonies was usually 100 per cent. and the margin of error in forming an estimate of its gravity must have been very slight.

In the Report of the Hants and Isle of Wight Beekeepers' Association for 1906 we read:

Twenty-five years' acquaintance with bees, bee men and bee life has not revealed anything so deadly or mysterious as this so-called bee paralysis of the Island.

Silver (1907), who toured the Island in 1907, gives his impressions in these words :

The sight of whole apiaries of 10 to 20 hives standing desolate and deserted in the middle of May is a most distressing one, and standing as I did, under a horse-chestnut tree in full blossom, in the grounds of the Rev. John Vicars, of Colbourne, situated in the centre of the Island, not a bee was visible on a beautiful spring day.

Complete apiaries died out in May and June just after swarming and when the hives must have been tenanted with young bees.

In support of the thesis that Tarsonemus wood $i$ has been entirely responsible for the losses known as Isle of Wight disease, Dr Rennie suggests that $T$. woodi is at present a parasite of bees in this country only. He assumes that Isle of Wight disease has never been clearly shown to exist in any other country and that no such persistent losses have ever occurred before in this or any other country, and discusses the possibility that a new disease has arisen through the migration of the mite from some other insect to the hive bee as host.

The evidence that the mite is not to be found in bees of other countries is confined to the negative results obtained by the examination of a few 
hundred bees that have accompanied queen bees sent to this country by post. But if the mite is the cause of a serious disease its occurrence in such bees would be rare. It is in the dwindling and unprofitable apiaries of other countries that search must be made, and until we get definite statements from foreign workers that the mite cannot be found in any of the troubles classed together as paralysis, the chances are in favour of its occurrence.

As to the long duration of Isle of Wight disease as compared with any other epidemic, we have no knowledge as to the number of years that apiaries have been re-stocked where paralysis is causing annual losses. In this country steady losses were formerly confined to districts. That such losses now occur all over the country is due to the altered method of beekeeping. And is it safe to assume that such losses have always been due to the same cause for the last seventeen years in this country and to some other cause in the various countries from which we have imported bees? Since Isle of Wight disease was first reported nearly all the bees of this country have disappeared. Their places have been taken by foreign bees, many of which have also died and the present bees of this country are mainly the descendants of recent importations from various parts of Europe, Asia, Africa, and America.

The German epidemic of 1859 followed the importation of foreign bees.

Our own losses in the early sixties of the last century came shortly after we commenced to import foreign bees and had started a crusade against the sulphuring of weak and redundant stocks. Prior to the starting of the epidemic in the Isle of Wight that island was a beekeepers' paradise, where the bees increased and gave surplus with little or no assistance from their owners. Nearly every village contained a number of skep beekeepers whose surplus colonies were sulphured in the autumn or exported as driven bees. With modern methods a steady importation of foreign bees took place. From 1898 to 1904 stocks and queens of foreign races were imported into the district where the disease is supposed to have originated. All the bees in that district were destroyed and the epidemic advanced across the island. Imms (1907) states that he was informed that the disease was so virulent that healthy swarms imported from the mainland were badly diseased within a week ${ }^{1}$.

Importations of foreign bees have been so heavy and continuous that it is difficult to believe that no diseases have been introduced with these bees during the present century. In reviewing the work that has been done on Isle of Wight disease in Scotland, the possibility suggests itself that at one time

1 The danger from trading and consequent intermixing appears to have been thoroughly grasped by our forefathers who recognised that it was unlucky to trade in bees.

The monks were great beekeepers and their migrations with their bees appear to have brought much bad luck. The traditional ceremonies that have been handed down among peasant beekeepers are often of pagan origin. The connection between Christianity and lack of honey is well shown in an old German adage given by Langstroth (1868):

"Bells' ding-dong and choral song

Deter the bee from industry;

But hoot of owl and wolf's long howl

Incite to moil and steady toil." 
what may have been a bacterial disease was being investigated as the Isle of Wight disease ${ }^{\mathbf{1}}$.

Tinsley (1918), in a bulletin issued by the West of Scotland College of Agriculture, states that he succeeded in infecting healthy bees with Isle of Wight disease by feeding them with sugar syrup in which the liquid contents of the intestines of sick bees had been incorporated. In one of Dr Rennie's earlier experiments (1919 A) Nosema spores in candy were fed to healthy bees in May. Crawling without Nosema was recorded as being present in June and the bees were found dead the following January. In 1915 also, pulped diseased bees were fed in honey to a stock on June 28th. The stock swarmed and both lots showed crawling in October and died out. The nearest bees were two miles away and remained healthy (Anderson and Rennie, 1916).

We assume that the Nosema spores were obtained from sick bees and that bacteria and other organisms were therefore unavoidably present in the candy. The results obtained by Dr Rennie may thus have been due to the organism that was present in the cases recorded by Tinsley. That organism is unknown, but the results suggest that it was situated in the alimentary canal.

\section{Conclusions.}

Acarine disease appears to be less virulent than the disease which swept across the Isle of Wight in the early years of this century. That the mite was causing damage at the same time is very probable but the investigations were centred on the acute and virulent disease.

It may be that most of the stocks affected with mites, but showing no symptoms of disease, die out sooner or later. But this does not demonstrate the existence of a new disease. It merely emphasises the soundness of the older system of beekeeping which considered it undesirable to retain any stock after the third season, the less desirable colonies being sulphured at an earlier period.

Although it may not be the cause of the Isle of Wight disease the discovery of the mite is of economic importance, revealing, as it does, one of the causes of the failure of modern beekeeping. Ever since the introduction of the "humane" system which saved the redundant bees and distributed them as "driven bees" throughout the length and breadth of the land, there has been a steady increase in disease which has helped to render the industry of honey production an unprofitable one. Before the rise of the Isle of Wight epidemic the losses were attributed usually to foul brood, although there was

1 The difficulty in classifying bee disease by symptoms is well shown by the following instance.

While the work on Nosema in its relationship to Isle of Wight disease was being carried out at Cambridge there ensued a heavy mortality of humble-bees which was found to be associated with the presence in the Malpighian tubes of a protozoon elosely resembling Nosema. In the year immediately past a similar mortality has been noticed in humble-bees, but the protozoon could not be found. The organism accompanying the mortality in 1921 was a nematode worm Sphaerularia bombi which undergoes development in the body cavity of the bee and eventually gives rise to huge numbers of larvae. In both years, the symptom of the trouble was inability to fly. 
much difference of opinion as to the amount of harm caused by this latter. malady. It is possible that Tarsonemus was present in the more severe cases and, consequently, a fresh series of observations are necessary.

It is the opinion of the writer that the mite will prove a comparatively harmless parasite in countries where two or more honey harvests and constant breeding activity are the rule. In some such districts we may expect to find the endemic centres of the disease.

If this opinion is confirmed, the mite will also be found in Australia, America and other countries as it is unlikely that we have been the only country to import it. In America there is a large amount of unexplained paralysis, and of winter and spring losses, while in Australia the subject of bee mortality is much discussed without anything very definite being known. Some of these troubles may be accompanied by mites.

In this country bees parasitised by mites are to be found all over the kingdom from Land's End to John o' Groats. The recognition of the dangers arising from modern procedure may eventually give rise to wiser and better methods of beekeeping and the discovery of the Aberdeen investigators may thus have far-reaching and unforeseen consequences.

\section{REFERENCES.}

Anoerson, J. (1916). The connection of Nosema apis and "Isle of Wight" Disease in Hive Bees. Proc. R. Physical Soc. of Edin. xx, 16.

Anderson, J. and Reinste, J. (1916). Observations and Experiments bearing on Isle of Wight Disease in Hive Bees. Ibid. xx, 23.

BeRLEPSCH, BARon von (1869). Die Biene und ihre Zucht. Mannheim.

BeUHNE, F. R. (1916). Nosema apis in Victoria. Journ. of the Dept. of Agric. of Victoria, xIv, 629.

Bevan, E. (1827). The Honey Bee. London.

Critchuow, B. P. (16. vii. 1904). Gleanings in Bee Culture Medina, Ohio, xxxII, 692.

Dadant, C. (1907). Langstroth on the hive and Honey Bee. Revised by Dadant. Illinois, U.S.A.

Fleming, G. (1871). Animal Plagues. London.

Graham-Smith, G. S., Fantham, H. B., Porter, A., Malden, W. and Bullamore, G. W. (1912). Report on the Isle of Wight Bee Disease (Microsporidiosis). Supplement No. 8, Journ. of the Bd. of Agric. XIX.

Hannemann (1909). Cited by Zander (1911).

HIRST, S. (192I). On the mite Acarapis woodi (Rennie) associated with the Isle of Wight Bee Disease. Annals and Mag. of Nat. Hist. Ninth Series, No. 42, 509.

Langstroth, L. L. (1868). On the Hive and Honey Bee. Third Edition. Philadelphia. See also Dadant (1907).

MaAsSEn, A. (1911). Zur Aetiologie und Epidemologie der Ruhr bei den Bienenvölkern. Mitteilungen a. $d$. K. Biolog. Anstalt $f$. Land- und Forstwirtschaft, 50.

MaLden, W. (ii. 1909). Further Report on a Disease of Bees in the Isle of Wight. Journ. of the Bd. of Agric. Xv, 809.

Nossbadmer, T. (1912). Einige Erfahrungen Über die Nosemakrankheit. Schweizerische Bienenzeitung (Reprint). REnNIE, J. and HARVEX, E. (1919 A). Isle of Wight Disease in Hive Bees. Journ. of the
Scottish Bd. of Agric. II, 176.

(1919 в). Nosema apis in Hive Bees. Ibid. $\pi, 511$.

RenNte, J., WHTTE, P. B. and HARvey, E. (1920). Isle of Wight Disease in Hive Bees. Trans. Roy. Soc. Edin. LI, 737.

ReNNIE, J. (1921). Notes on Acarine Disease. Bee World, III, 117.

SIIVER, J. (1907). Bee Disease in the Isle of Wight. Irish Bee Journal, vII, 10.

Trnstey, J. (1918). Preliminary Report on the Isle of Wight Bee Disease. Bulletin 85 W. of Scotland Agric. Coll. Glasgow.

ZANDER, E. (1911). Handbuch der Bienenkunde. 



PARASITOLOGY is published about four times a year. The numbers afterwards are issued in volumes each containing four numbers.

Papers for publication should be sent to Professor Geo. H. F. Nutrald, F.R.S., Longfield, Madingley Road, Cambridge. Other communications should be addressed to the University Press, Cambridge.

Papers forwarded to the Editor for publication are understood to be offered to PARASITOLOGY alone, unless the contrary is stated.

Contributors receive twenty-five copies of their papers free. Additional copies, not exceeding 100 (except in special cases), may be had at cost price : these should be ordered when the final proof is returned.

The subscription price is £2. 5s. per volume (post-free), payable in advance; single numbers $15 s$. net (double number 30s. net). Subscriptions may be sent to any Bookseller, or to MR C. F. CLAY, Marager, Cambridge . University Press, Fetter Lane, London, E.C. 4. 



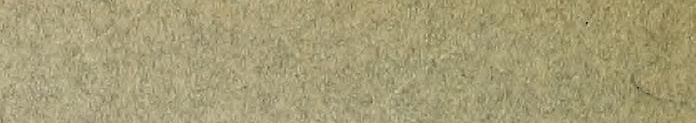

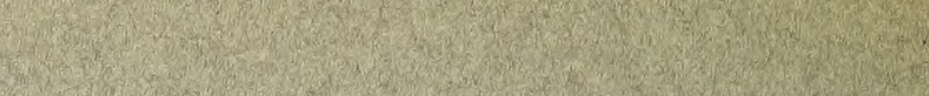

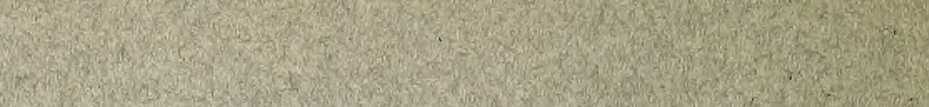

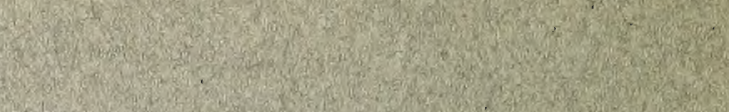

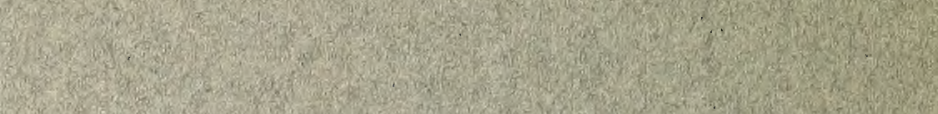

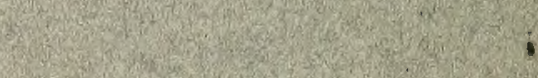

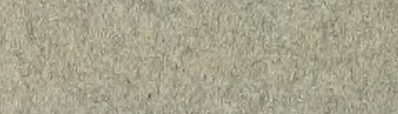

(x)

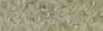

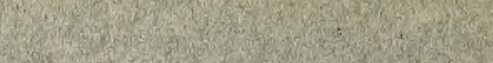

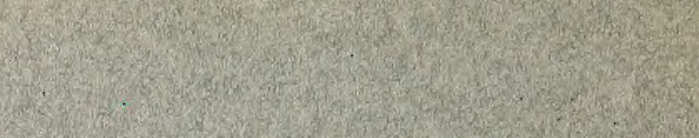

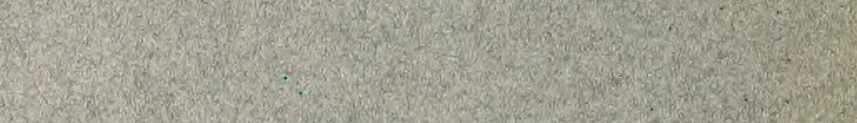

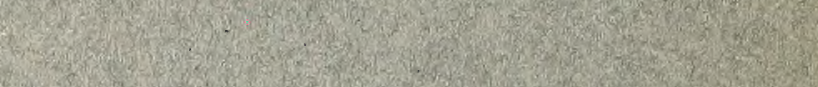

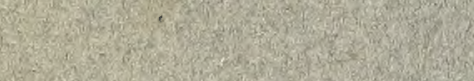

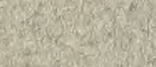

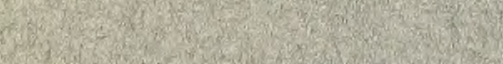

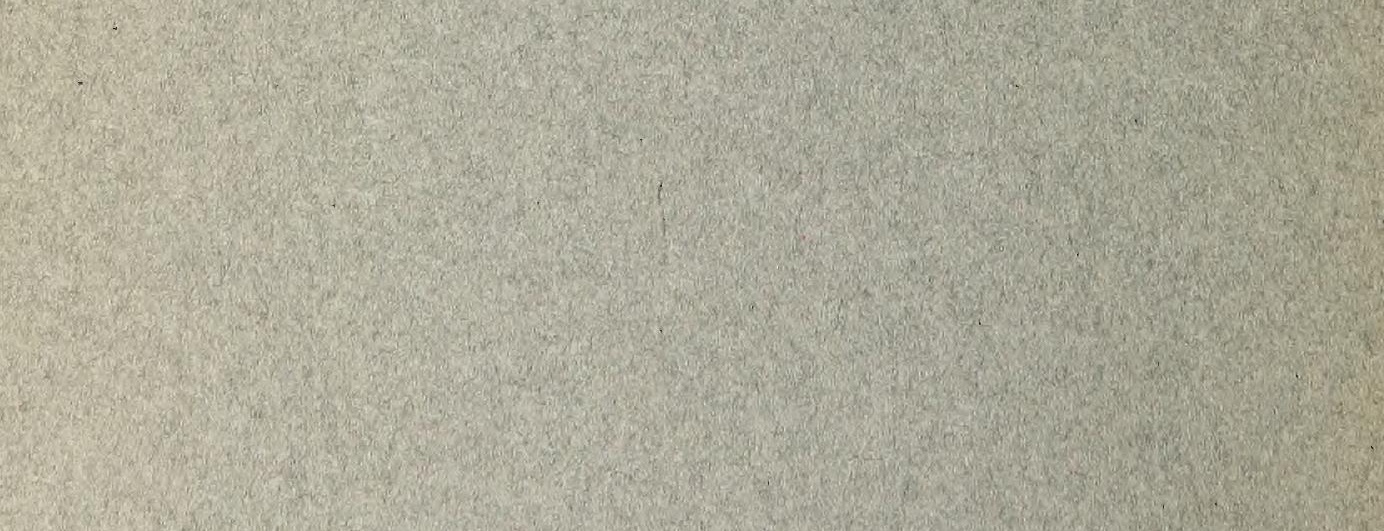

